\title{
Studying Gender and Sexualities with Qualitative Methods
}

\author{
David Smilde ${ }^{1} \cdot$ Rebecca Hanson ${ }^{2}$ \\ Published online: 9 August 2018 \\ (C) Springer Science+Business Media, LLC, part of Springer Nature 2018
}

Sometimes things just happen. In reviewing the manuscripts we had in the queue for the September issue, we realized that beyond any conscious intention half of them had to do with gender and/or sexualities. That is actually not surprising since about a third of the submissions we receive focus on gender and/or sexualities. In fact, we have always had to make sure that at least one of our editorial assistants was a GSS scholar, able to identify and locate viable reviewers.

Qualitative Sociology does not focus on publishing in specific research areas or sociological subfields. So why do we receive so many GSS submissions? We believe it is because qualitative methods lend themselves to studying the building blocks of gender expression and sexual identities - the interactional, the discursive, and the performative - and how these buttress systems of inequalities. Quantitative methods do a great job of detecting and measuring the effects of gender bias and discrimination in employment, education, and other domains of social life. But qualitative methods are particularly suited to unpacking the "how" of gender and sexualities - the layers of practices, discourses, histories, and identities that constitute and are constituted by them.

Gender and sexuality encompass (often binary) sets of categories related to the meanings assigned to assumed reproductive capacities made explicit in the everyday and inscribed into the unconscious, as well as the malleable and fluctuating content of those categories. Focused but open-ended participant observation, qualitative interviewing, and ethnographic readings of documents and archives can show us how people resist, remake or reify these categories, challenging or reproducing the inequalities that structure them. Qualitative methods can reveal the complicated and reciprocal processes through which assumptions about gender and sexuality guide interactions, become embedded in institutions, and differentially affect life chances.

In this issue, Rania Salem shows how the Egyptian middle class reproduces inequality through active constructions and reconstructions of gendered expectations around marriage. Salem shows how "waithood"- the process whereby young people wait to marry because they do not have the education, employment or material well being to form a new household-

Rebecca Hanson

beccara606@gmail.com

1 Tulane University, New Orleans, LA, USA

2 University of Florida, Gainesville, FL, USA 
results not simply from a scarcity of resources, but depends on gendered constructions of the division of labor and consumption practices that provide assurance to a bride's family that a man will provide for his dependent wife after the wedding. Matrimonial transactions, then, adhere to norms and ritualized situations that signal actors' dedication to dominant ideals of masculinity and femininity and the unequal roles they will come to occupy within marriage.

In a world in which there have been undeniable formal gains in gender equality, qualitative research can unpack and explain persistent inequalities. Examining the role of women in Italian mafias, Felia Alum and Irene Marchi push back against analyses that suggest that taking on high level positions in an organization - here, the mafia - signals that women have become empowered. They show this only happens at moments of crisis and that, while women gain status in the organization, they effectively do so by default. Wives, mothers and daughters serve as a sort of "reserve army" when men are killed, imprisoned, incapacitated or threatened. They suggest the term exploitation is closer to the mark than emancipation. By decoupling "rising in the ranks" from empowerment, the authors show that increased gender parity does not necessarily signal egalitarian gender relations. Chelsea Wahl and Stephen Ellingson provide a classic portrait of gender discrimination, looking at the contradictory way that the jazz world is simultaneously built upon a culture of meritocracy and gender essentialism. Women musicians may be initially accepted, but they are tested and evaluated in ways that men are not and may require the support of a wellestablished man in the scene; more often than not, assumptions about what women are physically capable of limits how far they can make it in the industry. When they seek more established roles in the jazz world they are often marginalized or pushed into feminized roles (as singers, for example). They push back by working with the discourse of meritocracy, fighting for established positions in the jazz world.

Alin Frantsman-Spector and Avihu Shoshana show that resistance is not the only response to discrimination and marginalization. They look at the obligatory therapy to which prisoners' wives are subject in Israel in order to obtain benefits for their children and imprisoned husbands. At first they resist the discourse of "vulnerable femininity" social workers foist upon them. But eventually they adopt an attitude of "strategic passing" in order to get what they need from state representatives. Over time the women learn to navigate social workers' discourse in order to obtain medical and financial benefits, suggesting that even in submission there is room for agency. However, as the authors show, in acquiescing to a discourse that is not their own to protect and provide for their families, prisoners' wives are made to engage in the reproduction of symbolic violence and gender (as well as ethnic) inequalities.

Both the Kelly and Gouchanour article as well as the piece by Frantsman-Spector and Shoshana demonstrate other "interactions" well captured by qualitative methods: the interactions between distinct yet interconnected systems of discrimination (class, race, ethnicity, and so on) that produce inequalities within gender categories as well as between them. Kimberly Kelly and Amanda Gochanour reveal how largely white evangelical anti-abortion activists "blackwash" abortion decisions. In trying to convince Black women not to have abortions, they do not seek to address the structural discrimination that puts Black women in the position of having an unwanted pregnancy. Rather, they appeal to racial stereotypes portraying them as abandoned by their communities and duped by abortion providers. Gowri Vijayakumar's article is instructive in considering how gender expression and sexual identities intersect to produce and impede activism in India. Vijayakumar shows that, while the formation of collective identity plays a crucial role in social movements, constructing a collective identity 
among sex workers is contingent on various factors, all of which revolve around the ways cis and trans women experience sex as work, including the different constraints they face in openly identifying as sex workers.

These articles vividly demonstrate how qualitative sociology can reveal the stubborn inequalities that still define our world in the 21 st century. These inequalities cannot be fully understood without studying in context, the practices, discourses, histories, and identities they are made of.

David Smilde is Charles A. and Leo M. Favrot Professor of Human Relations at Tulane University.

Rebecca Hanson is Assistant Professor in the Department of Sociology and Criminology \& Law and the Center for Latin American Studies at the University of Florida. 